Foro Interno. Anuario de Teoría Política

ISSN: $1578-4576$

https://dx.doi.org/10.5209/foin.65816

\title{
La participación política a través de dos perspectivas teóricas: el realismo-liberal y la democracia deliberativa ${ }^{1}$
}

\author{
Luciana Gabriela Soria Rico ${ }^{2}$
}

Recibido: 7 de mayo de 2018 / Aprobado: 31 de julio de 2019

Resumen. El presente trabajo reconstruye algunas de las tesis centrales de la familia realista-liberal de la democracia en relación con los liderazgos políticos y la participación política de la ciudadanía en sus dos fases de pensamiento: desde el elitismo hacia la poliarquía. Posteriormente se formulan algunas de las críticas que los teóricos deliberativos le realizan a este modelo en relación con el carácter minimalista de la participación y sus dificultades para combatir posibles poderes exógenos a la política. En este sentido, se presentan tres pilares del modelo deliberativo para superar esta aparente debilidad del modelo realista-liberal y generar autonomía política o, al menos, combatir su heteronomía a través de: 1) la transformación de preferencias, 2) el ejercicio de una razón comunicativa, y 3) una fundamentación epistémica de las creencias morales.

Palabras claves: democracia realista-liberal; democracia deliberativa; participación ciudadana; poderes exógenos.

\section{[en] Political Participation from Two Theoretical Perspectives: Liberal- Realism and Deliberative Democracy}

\begin{abstract}
This article reconstructs some of the central theses of the liberal-realist families of democracy in relation to political leadership and citizen participation in the two phases of thought that go from elitism to polyarchy. Deliberative democracy theory offers a critique of the minimalist view of participation and of liberal theories' weakness in addressing the powers that are external to politics. In this sense, three pillars of the deliberative model are formulated here in order to overcome this weakness of liberalism and generate political autonomy or combat heteronomy, through: 1) transformation of preferences, 2) exercise of a communicative reason, and 3) epistemic foundations of moral beliefs.
\end{abstract}

Keywords: liberal-realist democracy; deliberative democracy; citizen participation; exogenous powers.

Cómo citar: Luciana Gabriela Soria Rico, "La participación política a través de dos perspectivas teóricas: el realismo-liberal y la democracia deliberativa": Foro Interno. Anuario de Teoría Política, vol. 19 (2019), pp. 29-51.

\footnotetext{
$1 \quad$ Agradezco a los evaluadores anónimos de Foro Interno. Anuario de teoría política por sus valiosos comentarios y críticas.

2 Facultad de Humanidades y Ciencias de la Educación. Universidad de la República Oriental del Uruguay (Uruguay)

E-mail: lucianasoriarico@gmail.com
} 


\section{Introducción}

En el campo de la teoría política contemporánea se presentan diversas visiones en disputa respecto a qué nos cabe esperar de la democracia y si es posible y deseable una forma óptima en su funcionamiento. En este debate, se ponen en juego dos familias teóricas a las que a grandes rasgos podríamos distinguir como: la vertiente realista y la prescriptivista. Ambas sostienen diferencias metodológicas y asumen supuestos teóricos divergentes. Mientras que las primeras tienen un discurso descriptivo acerca de democracias reales sobre las que buscan dar cuenta, respaldándose muchas veces en estudios comparados, las visiones prescriptivas se focalizan en fundamentar criterios normativos con los que podríamos revisar las democracias presentes y futuras. El realismo de las primeras no está exento de juicios normativos, aunque no siempre se realicen de modo explícito; las segundas, sin embargo, asumen la carga normativa con un fuerte componente crítico del estado actual del funcionamiento democrático y proyectando otros modos posibles de constitución. Si bien ambas familias teóricas tienen distintas discursividades, ambas poseen un trasfondo normativo con el que se comprometen sus representantes teóricos centrales y por ello es posible compararlas.

Muchas veces la visión realista podría coincidir con el liberalismo político, pero no sería acertado afirmar que todos los autores liberales son realistas. John Rawls (1921-2002) sería un claro contraejemplo, por ello liberalismo político no será un término feliz para denotar la totalidad de la familia realista de la democracia. Por tanto, en este artículo adoptaremos la expresión realismo-liberal para referirnos al conjunto de autores que pretenden dar cuenta del mecanismo efectivo de la democracia y, a su vez, privilegian la libertad de no interferencia como un derecho que debe ser salvaguardado. Dentro de la familia prescriptivista de la democracia nos centraremos en el modelo deliberativo por entender que este se manifiesta de modo sistemático y potente a través de distintas tradiciones filosóficas y como una alternativa teórica al realismo-liberal.

Ambas perspectivas disputan diversos aspectos normativos de la democracia, aunque en algunos autores el compromiso normativo se presenta de modo más explícito y en otros de modo más solapado, en este último sentido dan cuenta de los vacíos teóricos que presentan las descripciones empíricas. En el presente artículo, me centraré en el rol de la ciudadanía respecto al grado de participación política que estos modelos esperan de la misma; es decir, en cuáles son los criterios por los que definen y evalúan la participación cívica.

\section{La familia realista-liberal de la democracia}

\section{1. La primera ola}

En su libro ¿Qué es la democracia? Giovanni Sartori (1924-2017) plantea que la caída del bloque comunista nos deja en presencia de un vencedor absoluto: la democracia liberal. Su victoria es como principio de legitimidad al que se suscribe buena parte del mundo ${ }^{3}$. Coincidiendo con distintos teóricos, Sartori entiende que la democracia liberal se ha impuesto ideológicamente en el mapa occidental de cier-

Giovanni Sartori, ¿Qué es la democracia?, Taurus, Madrid, 2003, pp. 366-367. 
tos países industrializados. En el presente artículo las denominaremos democracias liberales-realistas porque dentro de un marco teórico liberal pretenden ofrecer un sentido descriptivo y explicativo de la realidad. Esta perspectiva se caracteriza por su crítica a los postulados de la democracia clásica, fundamentalmente a la idea de la voluntad popular de raíz rousseauniana; entiende que entre las concepciones del bien que conviven bajo las democracias occidentales es imposible postular un bien homogéneo, así como una voluntad política unánime para todos, pues considera que la noción del "poder del pueblo" encierra diversas inconsistencias o contradicciones de difícil resolución. Por ejemplo, Sartori subraya la ambigüedad lingüística del concepto de "pueblo" y sus diversas interpretaciones, las que oscilan desde su concepción totalizadora que abarca a "todo el mundo" o aquella que se limita a "la clase baja", entre otras. A esta crítica Sartori añade los cambios que ha sufrido la vida colectiva que obstaculiza la aplicabilidad de la concepción clásica: aquella polis pequeña y cohesionada en la que se acuñó el término demos ha sido sustituida por una "sociedad de masas" difusa y atomizada ${ }^{5}$. Frente a este planteamiento cabe preguntarnos: ¿qué resta del pueblo en las sociedades actuales? Los análisis realistas de la democracia parten de esta pregunta y buscan redefinirla tomando en cuenta las nuevas estructuras de la vida social.

Siguiendo esta línea, los autores realistas pretenden dar cuenta de cómo se comportan los votantes en las democracias contemporáneas y de cómo reaccionan los sistemas políticos occidentales frente a ello ${ }^{6}$. A partir de observaciones empíricas en países desarrollados que se toman como muestra de la investigación se pretenden extraer las reglas del funcionamiento democrático. De estas observaciones se infiere que, de la interacción de la libre oferta de los partidos y de la libre elección de los votantes en el campo político, se deriva una dinámica democrática y que el valor y la calidad de la misma emerge en este proceso competitivo. Para este modelo, del funcionamiento regular de la democracia se desprende una cierta normatividad; esta es concebida como un subproducto de la competencia política, es decir, como una práctica de gobierno que emerge de un juego institucional. Este juego institucional implica la existencia de una serie de actores y de reglas que definen y ordenan el universo de lo político. Uno de los teóricos centrales del realismo-liberal, Anthony Downs, sostiene que en este universo los agentes deben contar con ciertos derechos políticos de elección y decisión y ciertas condiciones objetivas como la libertad de los medios de comunicación y la organización de partidos políticos, así como la celebración de elecciones periódicas ${ }^{7}$. Como el simple hecho de que se celebren elecciones no basta para que estas sean competitivas, por ello se necesitan otras reglas que

$4 \quad$ "Demos en el siglo quinto antes de Cristo significó la comunidad ateniense (o algo semejante) reunida en la eklesía, la asamblea popular. Sin embargo, demos puede asimilarse a todos; o a los polloí, los muchos; o a los pleíones, la mayoría o a los óchlos, la multitud (el sentido degenerado)”. Giovanni Sartori, Teoría de la democracia, Alianza, Madrid, 1987, pp. 42-43.

Ibidem.

Crawford Brough Macpherson, La democracia liberal y su época, Alianza, Madrid, 1997, p. 96.

“...la existencia de por lo menos dos partidos políticos que compiten por el gobierno en las elecciones, la celebración de elecciones periódicas, la posibilidad de un único voto por elector, que el partido o la coalición de partidos que reciben el apoyo de la mayoría de los votantes son los que están autorizados para tomar el poder del gobierno, que aquel partido que pierde las elecciones nunca va a usar la fuerza u otro medio ilegal para sacar a los partidos gobernantes del poder". Anthony Downs, An Economic Theory of Democracy, Harper Collins Publishers, New York, 1957, p. 24. 
la acompañen ${ }^{8}$. El buen funcionamiento de la democracia implica entonces ciertas condiciones mínimas, tales como la presencia de un sistema de partidos organizado, el sufragio universal y el derecho ciudadano a una elección libre de coacciones, entre otras 9 . Una vez dadas estas condiciones, se entiende que los partidos políticos son agentes activos de organización y regulación de lo político: cuando los partidos políticos compiten ponen en movimiento la infraestructura institucional de la democracia. En este contexto emergerán las propuestas políticas dirigidas a satisfacer las preferencias de los ciudadanos. El éxito de estas dependerá de su capacidad para capturar la mayoría de los votos.

Para ofertar propuestas de valor electoral los partidos deberán desarrollar estrategias para comprender y captar las preferencias ciudadanas y mediante qué políticas públicas podrían satisfacerse. En este enfoque se considera que la rivalidad entre los partidos políticos es saludable para la democracia porque incentiva la calidad de las políticas públicas que los partidos ofrecen a los ciudadanos al mismo tiempo que promueve la rotación en el poder. Esta dinámica se mueve con base en los acuerdos que los partidos alcanzan a través de la mediación entre las distintas preferencias: "Los partidos no buscan el bien común, sino que buscan transacciones entre intereses en conflicto. La deliberación es sustituida por la negociación" ${ }^{10}$. En consonancia con esto, la tesis central del modelo realista-liberal es que el motor de la democracia es la competencia partidaria.

¿A través de qué autores se encarna este modelo? De la mano primeramente de Max Weber (1864-1920) ${ }^{11}$ y posteriormente de Joseph Schumpeter (1883-1950) ${ }^{12}$ y Anthony Downs ${ }^{13}$ se consolidó la visión realista de la democracia liberal en el terreno teórico, mientras que Robert Dahl (1915-2014) a través de la categoría de poliarquía amplió la mirada de este enfoque planteando que no hay un único grupo dirigente sino una multiplicidad de ellos compitiendo por el poder ${ }^{14}$. Por último, Giovanni Sartori agregó que las democracias reales realizan una selección de élites de mérito, por ello son poliarquías selectivas ${ }^{15}$.

De Weber a Sartori hay un espectro amplio y heterogéneo de pensadores que se podrían ubicar en las filas del realismo-liberal democrático. Para la presente exposición son elegidos aquellos que destacan en la trama de esta tradición. A partir de esta selección, me interesa indagar en la visión de la participación política ciudadana que sustentan los representantes de esta tradición.

Un antecedente reconocido del modelo realista-liberal es Max Weber. Este sostiene que la aparición de los partidos políticos modernos supone el desplazamiento del dominio de los notables y los parlamentarios hacia nuevas formas organizativas, impulsadas por el desarrollo del "derecho a las masas al sufragio, de la necesidad de hacer propaganda y organizaciones de masas y de la evolución hacia una direc-

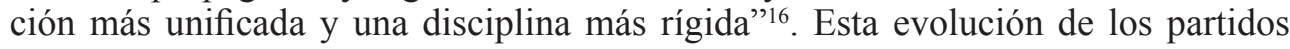

\footnotetext{
8 Adam Przeworski, Qué esperar de la democracia: límites y posibilidades del autogobierno, Siglo Veintiuno, Buenos Aires, 2010, p. 191.

Downs, An Economic Theory of Democracy, p. 24.

Prezeworski, Qué esperar de la democracia, p. 70.

Max Weber, Economía y sociedad, Fondo de Cultura Económica, México, 1964, pp. 1103-1117.

Joseph Schumpeter, Capitalismo, socialismo y democracia, Folio, Barcelona, 1984.

Downs, An Economic Theory of Democracy, 1957.

Robert Dahl, La poliarquía: participación y oposición, Tecnos, Madrid, 1989.

Sartori, ¿Qué es la democracia?, pp. 167-169.

Max Weber, El político y el científico, Alianza, Madrid, 1998, p. 129.
} 
democratiza decisiones trasladándolas fuera del Parlamento, a veces en manos de empresarios (como el boss en Estados Unidos o el election agent Inglaterra) y otras de funcionarios a sueldo. Así, se instala un proceso nuevo para la selección de los dirigentes del partido: aquellos a quienes siga la maquinaria del partido serán sus jefes ${ }^{17}$. Esta "maquinaria del partido" que se desarrolla rápidamente en ciertos países como Estados Unidos instaura una democracia plebiscitaria, donde se destacará el objetivo de controlar una cierta cantidad de votos. El presidente Andrew Jackson (1767-1845) catalogó esta nueva forma partidista norteamericana como spoil system, poniendo de manifiesto su transformación en organizaciones desprovistas de convicciones ideológicas definidas, marcadas por la ambición de cargos y cuyos programas de gobierno se modifican en cada elección ${ }^{18}$. Los empresarios políticos son conductores de partido que por su propia habilidad van capturando una red cada vez más extensa de votos; una vez conseguido esto entran en relación con empresarios vecinos ${ }^{19}$. Estos son patrocinadores que retribuyen a sus seguidores con diversos cargos y privilegios ${ }^{20}$ y son una pieza central para la organización del partido, porque consiguen y centralizan la mayor parte de recursos financieros. Su móvil central es obtener poder y contactar con los notables o líderes políticos del partido, pero no suelen ocupar cargos ni aparecer en la escena pública, operan fundamentalmente en las sombras ${ }^{21}$. Junto a estos patrocinadores, aparecen los caudillos políticos que trabajan junto a ellos como las caras visibles en la competencia política. Si bien Weber analiza esta evolución de los partidos políticos en el contexto norteamericano e inglés, y entiende que, frente a la pasividad creciente del electorado propia del mundo burocrático moderno, esta fórmula de liderazgos políticos (carismáticos o no), profesionalización creciente y eclipse del modelo del partido de convicción podría extenderse a otras democracias ${ }^{22}$.

Siguiendo las tesis de Weber, Schumpeter considera que los caudillos o líderes políticos cuentan con los recursos necesarios para el ejercicio del poder, al mismo tiempo que desarrollan las competencias adecuadas para ello. En esta línea sostiene que las condiciones formales que sustentan la democracia contribuyen a la formación de los líderes políticos. Schumpeter entenderá que "la característica de un gobierno democrático no es la ausencia de elites, sino la presencia de más elites en competencia entre sí por el voto popular" ${ }^{23}$. Los liderazgos políticos constituyen elites que se disputan el poder político a través de la competencia política. En este modelo, la soberanía se ejerce a través de la elección de los representantes y, por consiguiente, se entiende que la toma de decisiones se produce de modo indirecto. En ello radica la relevancia del voto.

En un contexto de competencia, los políticos actúan según la regla de las "reacciones anticipadas" ${ }^{24}$; esto es, las decisiones políticas están condicionadas por las expectativas acerca de cómo reaccionará el electorado. Así, los políticos toman decisiones calculando la reacción de los votantes y el poder de elección de los votan-

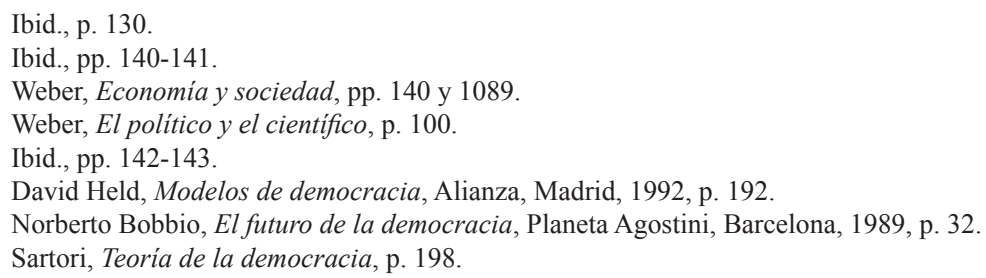


tes produce como resultado que los políticos busquen respaldo en el poder de sus electores. El electorado ejerce su poder a través del voto y de este modo controla a los líderes a través de la renovación, o sustitución de su mandato, pero no durante su ejercicio. A la luz de las investigaciones de la psicología de las masas de Gustave Le Bon (1884-1931), Schumpeter sostiene que cuando los individuos entran en la esfera política descienden a un plano inferior de actividad mental. Su pensamiento se vuelve "asociativo y afectivo" "25, es casi imposible que actúen de forma sistemática y ordenada, la masa electoral es incapaz de organizarse políticamente. Por ello, el papel de los partidos es crucial ${ }^{26}$.

Schumpeter parte de la crítica a la idea de voluntad general y del bien común de la democracia clásica, la que según Adam Przeworski se centra en los siguientes cuatro puntos: (1) no hay un bien común definido de una vez de modo concluyente; (2) las preferencias de los individuos, que los utilitaristas entendieron como auténticas preferencias de los ciudadanos, son en realidad moldeadas de modo exógeno; (3) en el caso en el que pudiera emerger una voluntad general sería difícil determinar si esta pudiese arribar a un bien común; (4) aún en el caso de que pudiéramos acceder al bien común sería problemático cómo podría instrumentalizarse ${ }^{27}$. En su descripción de la democracia clásica se le objeta a Schumpeter que confunde la visión bienestarista del utilitarismo con la idea de soberanía popular rousseauniana ${ }^{28}$.

Siguiendo los pasos de Schumpeter, Downs sostiene que en lo que se refiere al ciudadano medio hay dos decisiones políticas que exigen información: la decisión sobre qué partido votar y la decisión sobre cuáles son los asuntos en los que se debe ejercer influencia directa ${ }^{29}$. En el caso del voto, el ingreso marginal de información se evaluaría por la ganancia obtenida de "votar correctamente", esto es, la utilidad que un votante obtendría si apoyara al partido que realmente le diera más utilidad en lugar apoyar a otro que no se la diera. Sin embargo, en un amplio electorado, un solo voto no es sustancialmente decisivo en la elección, la probabilidad de que un voto determine qué partido va a ganar es muy baja. Por tanto, a pesar del fracaso que pueda significar la pérdida de un votante si ganara el "partido incorrecto", el "costo" de la pérdida sería tan pequeño que el incentivo para informarse y obtener mayor calidad de información sería nulo ${ }^{30}$. A partir de lo anterior, Downs concluye que es irracional para la mayoría de los votantes adquirir información política con propósitos de voto. Si el electorado estuviese bien informado acerca de cuáles son las mejores políticas para sus intereses, el gobierno se vería forzado a seguirlas para evitar su fracaso. Pero cuando se ponen en práctica las políticas, estas benefician a cada uno de los electores independientemente de si contribuyeron o no con su voto:

Así pues, cuando los beneficios son indivisibles cada individuo tiene siempre motivos para evadir su participación en el coste de obtenerlos. Si supone que el comportamiento de los demás está dado, el que reciba o no beneficios no dependerá de su propio esfuerzo; por consiguiente, el esfuerzo más racional para él es minimizar este coste, es decir, permanecer políticamente desinformado. Puesto que todos los

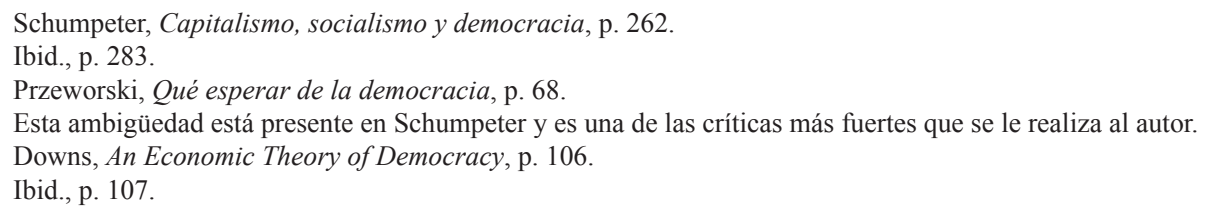


individuos razonan del mismo modo, ninguno contribuye al coste y no se generan beneficios $^{31}$.

Por tanto, los individuos recibirán o no los beneficios de las políticas independientemente de cuan bien informados se encuentren. Cuando nadie está bien informado, el individuo no puede generar esos beneficios informándose a sí mismo porque para lograrlo es necesario un esfuerzo conjunto.

\subsection{La segunda ola}

Desde su obra temprana titulada Who Governs?, Dahl entendió que la verdadera unidad de análisis de los sistemas políticos no son las personas o los partidos políticos, sino los grupos de interés: "Si preguntamos ¿quién gobierna?, la respuesta no está en las masas ni en sus líderes, sino en ambos juntos. Los líderes complacen los gustos de las masas y a cambio utilizan la fuerza que les da su lealtad para debilitar y quizá incluso aniquilar toda su oposición al dominio"32. En esta obra, Dahl acudió a múltiples métodos de investigación (tales como la historia política, las encuestas, entrevistas, análisis detallados de eventos, entre otros. Esto se hizo necesario debido a la importancia de observar de cerca lo que realmente sucedió, no lo que supuestamente tuvo lugar) e investigó distintas controversias políticas sobre la toma de decisiones en la renovación urbana y las decisiones en la educación pública. Los puntos de vista que recogió sobre la importancia de los procesos vitales fueron evidencias para comprender las realidades del poder dentro de la democracia ${ }^{33}$. Tomando como modelo de referencia la ciudad de New Haven del estado de Connecticut para su investigación, Dahl llegará a la conclusión de que los gobiernos democráticos suponen una relación ambigua entre los líderes y los ciudadanos marcada por la reciprocidad, donde las acciones de unos impactan sobre los otros. Si bien hay una proporción relativamente pequeña de líderes que ejerce influencia directa relativamente intensa sobre todas las opciones importantes que influyen en la vida de la asociación política, también está presente el poder popular sobre las políticas de los líderes. Por ello, "el control de las minorías por parte de los líderes dentro de las asociaciones no es necesariamente incompatible con el control popular de los líderes a través de los procesos electorales" 34 .

Dentro de la familia realista de la democracia son de gran relevancia los aportes de Robert Dahl al campo de la teoría política. En sus obras posteriores a Who Governs? Se destacarán dos características de la democracia: el derecho a participar y el derecho a la contestación pública. Esta última será una condición de impronta liberal: el derecho a retar a las políticas de gobierno en su creación y aplicación ${ }^{35}$. La introducción de las dos dimensiones, (1) oposición o liberalización y (2) participación, permiten a Dahl representar las diferencias entre los regímenes según se aproximen o distancien de dos extremos: las "hegemonías cerradas" que niegan ambas dimensiones y las "poliarquías" que las realizan. La poliarquía es entonces una función de

\footnotetext{
Ibid., p. 108.

Robert Dahl, Who Governs?, Yale University Press, Massachusetts, 1976, p. 5.

Leonard Tivey, "Robert Dahl and American Pluralism", en Leonard Tivey y Anthony Wright (eds.), Political Thought since 1945: Political, Science, Ideology, Edward Elgar Publishing Limited, England, 1992, p. 97.

34 Dahl, Who Governs?, p. 101.

35 Tivey, "Robert Dahl and American Pluralism", p. 97.
} 
la participación no sólo electoral sino comunicadora de preferencias con el objetivo de influir en el debate público ${ }^{36}$. El autor entiende que un gobierno hegemónico (unitario y centralizado) no concuerda con la democracia en la medida en que esta se ejerce entre distintos grupos de interés que compiten entre sí: esta es la poliarquía. Definida como un sistema de control político dónde los principales funcionarios del gobierno "son inducidos a modificar su proceder para ganar las elecciones en competencia política con otros candidatos, partidos y grupos" ${ }^{\prime 37}$. En este sentido, suponen un número importante de actores políticos con cierta autonomía entre sí y respecto al gobierno. A su vez suponen un aumento de los derechos políticos individuales (supone la ampliación de ciudadanía y derechos tales como a un proceso judicial ecuánime) y la consolidación de ciertas instituciones (funcionarios electos, elecciones libres e imparciales, sufragio inclusivo, derecho a ocupar cargos públicos, etc. $)^{38}$. La poliarquía es el régimen que más se acerca al ideal democrático de participación plena, debido a que recoge el pluralismo reinante donde los conflictos se resuelven entre cierto número no restringido de actores.

¿Las poliarquías limitan la posibilidad de la participación ciudadana en sintonía con los modelos expuestos anteriormente? Dahl entiende que las poliarquías se dan en sociedades plurales en las que la autoridad y el control circulan entre una variedad de individuos, grupos y asociaciones y organizaciones, cancelando la posibilidad de que se focalicen en un centro único; a su vez, promueven actitudes y creencias favorables a la democracia y, finalmente, cuentan con limitaciones legales y constitucionales para el ejercicio de la coacción gubernamental ${ }^{39}$. Estas poliarquías tienden a originarse en sociedades industrializadas dónde las aspiraciones que contribuyen a crear y alentar generan un poder disperso, no centralizado. Por ello las democracias se caracterizan por la difusión del poder y minimizan la idea de un sector hegemónico dirigente. Si bien el autor la mantenía como una hipótesis relevante, la relación entre industrialización y democratización de la sociedad es problemática ${ }^{40}$. A partir de lo anterior podemos afirmar que Dahl no sigue exactamente la misma línea que sus antecesores realistasliberales en lo que respecta a la centralidad del poder y los obstáculos a la participación política de la ciudadanía siempre que se dé a través de grupos de interés.

Simultáneamente, Dahl entiende que las teorías que postulan la dominación de una minoría sobre la mayoría son deficitarias en su retrato de las democracias reales. Por consiguiente, entiende que el modelo de las elites conlleva una importante carga de ambigüedad semántica, de modo que ha sido difícil corroborarla. Por ejemplo, cuando no aparece una elite visible al mando se apela a la idea de "dirigentes secretos" detrás de los primeros que son manejados por estos ${ }^{41}$. Señala distintas debilidades de estas teorías tales como no definir claramente quienes son la minoría dominante. A principios del siglo diecinueve, se hace evidente que la constitución del gobierno no son los grandes propietarios — como muchas de estas teorías aluden sino "una aristocracia colegiada", la que sería esencial identificar para "verificar o refutar una teoría sobre ella" ${ }^{42}$. Dahl considera que, si bien estas teorías dan testimo-

\footnotetext{
Dahl, La poliarquía: participación y oposición, pp. 17-19.

Dahl, La democracia y sus críticos, Paidós, Buenos Aires, 1991, pp. 156-160.

Ibid., pp. 266-267.

Dahl, La poliarquía: participación y oposición, p. 92.

Un contraejemplo claro es China. Agradezco a uno de los evaluadores de Foro Interno esta observación.

Dahl, La democracia y sus críticos, pp. 201-202.

Ibid., pp. 321-322.
} 
nio de las desigualdades, tienen un "alto grado de generalidad" y son "conceptualmente ambiguas", lo que hace que resulte imposible verificarlas ${ }^{43}$; $y$, por otra parte, no cuentan con elementos convincentes para sostener que en las poliarquías "una minoría dirigente domina" al resto ${ }^{44}$.

En su artículo The Concept of Power sostiene que no se ha podido verificar con validez que haya una elite de poder en los Estados Unidos o en una comunidad lo$\mathrm{cal}^{45}$. Sin embargo, no pasa por alto que cuando las minorías son pequeñas, débiles y carecen de resortes políticos sustanciales, aún en un régimen de poliarquía, podrían ser segregadas, como sucedió en la Atenas clásica y en el sur de Estados Unidos. En ambos casos convivió una democracia dualista: "competitiva respecto a un grupo dominante y hegemónica con respecto a una minoría segregada"46.

Heredero del pensamiento de Dahl, Sartori sostiene que no podemos separar la carga normativa de la democracia de lo que esta efectivamente $\mathrm{es}^{47}$, aunque esto no suponga la negación de los ideales sino su "administración". Por ello, la democracia requiere un retrato tanto descriptivo como normativo ${ }^{48}$. En este sentido entiende que, si maximizamos el ideal democrático de participación entonces se produciría la "quiebra del sistema" criterios orientadores. Es el proceso competitivo de reclutamiento de líderes donde emerge la democracia como tal; allí se genera una poliarquía abierta que atribuye el poder al pueblo y valora la responsabilidad de los líderes ${ }^{50}$. Sartori sostiene que los procesos de dirección e influencia de las democracias son "complejos y esquivos", no necesariamente suponen que "las minorías tengan escaso poder o que se anulen entre sí". Por lo contrario, las democracias actuales obedecen a un "modelo de liderazgo de las minorías, caracterizado por una multiplicidad de grupos de poder entrelazados, envueltos en maniobras de coacción"51. A su vez entiende que las democracias se valen de un control recíproco de los líderes y ciudadanos, para ello el pueblo debe contar con un poder garantido y sin trabas para ello, en este sentido los procesos electorales serán claves ${ }^{52}$.

Frente a las acusaciones que recibe la familia del realismo-liberal, Sartori plantea que aquellos que los acusan de elitistas por cuestionar o negar la participación política de las masas desvían la discusión central, que no se reduce a "cuánta participación podemos tener" sino "si la democracia participativa puede sustituir a la representativa". Pero en este punto no realizan ningún aporte desde el punto de vista constructivo a la democracia representativa ${ }^{53}$. En la visión de Sartori, el poder de conducir la democracia no está en manos de minorías sino en los liderazgos que se articulan en torno a ellas, la competencia política será un móvil fundamental de la democracia porque los líderes políticos se ven constantemente expuestos a la posibilidad de remoción electoral. Por ello siempre estarán atentos a la reacción de los

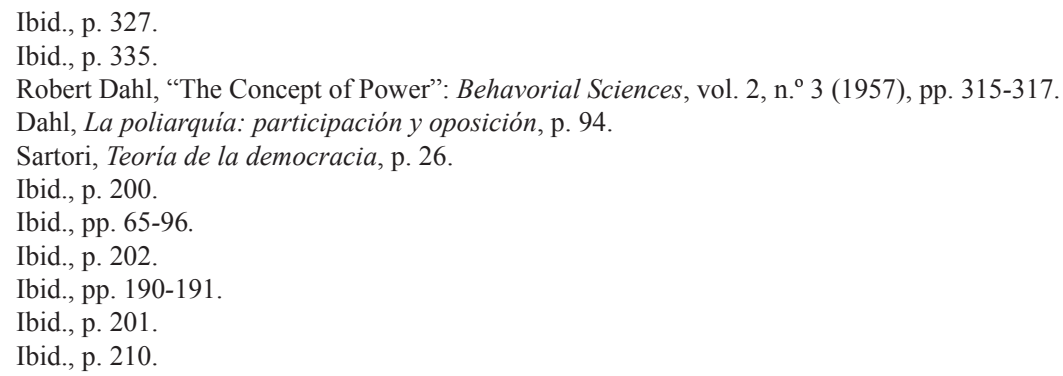


votantes frente a su actuación y de las propuestas de sus competidores en el escenario político. Carole Pateman sostiene que si bien para Sartori "el pueblo" tiene la potestad de "reaccionar" frente a las decisiones de los líderes políticos carece de la potestad de "actuar" 54 .

Por su parte, Norberto Bobbio (1909-2004), afirma que el procedimiento normal para tomar decisiones en la democracia representativa -única forma existente y funcionamiento de la democracia ${ }^{55}$ — es aquel en el que estas son fruto de negociaciones y acuerdos entre grupos que representan distintas fuerzas sociales (sindicatos) y fuerzas políticas (partidos), en lugar de una asamblea en la que funciona el voto y la mayoría ${ }^{56}$. Y cuando los líderes partidistas negocian, el papel de los votantes se reduce al mínimo. Al igual que Sartori, entiende que lo último que estos pueden hacer es ratificar los acuerdos ${ }^{57}$. Como efecto de ello, Bobbio constata un creciente desinterés en la política del ciudadano corriente ${ }^{58}$, pero al mismo tiempo entiende que un exceso de participación podría producir el efecto de saciedad de la política y el aumento de la apatía electoral, mientras que un exceso de mediación grupal tiene el riesgo de producir su propia muerte ${ }^{59}$.

\section{Críticas al realismo - liberal}

Una primer ola realista-liberal entiende que en las democracias sólo podemos atribuir participación política a los líderes porque son quienes cuentan con las aptitudes para tomar las decisiones públicas, no así la ciudadanía que naturalmente tiende o a apasionarse y tomar decisiones desacertadas o bien a desinteresarse y relegar las decisiones a otros. Esto último se retroalimenta con una cierta apatía política cívica que naturalmente aflora en las democracias occidentales. Esta primera ola no considera que la participación ciudadana sea un imperativo político en sí para el funcionamiento democrático. Varios de los primeros teóricos de esta vertiente consideran que una maximización de la participación ciudadana que redunde en instancias de participación directa podría llegar a obstaculizar el buen funcionamiento del sistema político. Sin embargo, en su evolución histórica la segunda ola de realismo-liberal, bajo una impronta pluralista, entenderá que la participación política no se practica de modo individual en la esfera pública, sino a través de ciertas agrupaciones o colectivos. Las decisiones políticas se toman a través de la transacción de los líderes partidarios. Estos buscan transacciones mediante la negociación entre los distintos intereses en conflicto, y dichas transacciones estarán sujetas — como afirma Przeworski- a la "ratificación constante de los votantes"

\footnotetext{
Carole Pateman, Participación y teoría democrática, Prometeo, Buenos Aires, 2015, p. 231.

Bobbio, El futuro de la democracia, p. 31.

Ibid., pp. 89-104.

Przeworski, Qué esperar de la democracia, p. 70.

Bobbio, El futuro de la democracia, p. 39.

59 "La abstención del voto ha aumentado, aunque hasta ahora no de manera preocupante, y, por lo demás, la apatía política no es en modo alguno un síntoma de crisis de un sistema democrático, sino, como suele observarse, una señal de su perfecta salud: basta de interpretar la apatía política no como un rechazo del sistema, sino como benevolente indiferencia". Ibid., p. 91.

60 "La especificidad de la democracia se reduce a que estas transacciones sean avaladas de vez en cuando por los votantes. Pero éstos no pueden hacer más nada que aprobar los tratos negociados por los dirigentes partidarios o expulsar a los canallas...". Przeworski, Qué esperar de la democracia, p. 70.
} 
La evolución hacia un pluralismo crítico de la familia realista-liberal, donde tanto la participación como la oposición al gobierno son instancias relevantes para la democracia, aleja a esta segunda ola de sus primeros pasos en la defensa de un liderazgo de centralizado, el pluralismo democrático cuestiona esta centralidad estable. Sin embargo, persiste la convicción de que el exceso de democracia es vicioso para una competencia eficaz. Por tanto, es necesario mantener ciertos niveles de apatía política, tal como expresó Bobbio.

Diversas voces críticas objetan al realismo-liberal que el modelo que describen y legitiman se focaliza de modo tal en los liderazgos que no vislumbra ningún tipo de control por parte de los ciudadanos para la toma de decisiones político-partidistas, por ello redundan en una visión centralizada del poder que habilita a los poderes exógenos al sistema político para que se infiltren en la toma de decisiones. Esto perjudicaría la democracia en la medida en que se terminan reproduciendo poderes hegemónicos en el campo de la política tales como el mercado o la burocracia. Quiénes se hacen eco de esta crítica — Jürgen Habermas, Gerald Cohen (1941-2009), Iris Marion Young (1949-2006), entre otros - sostienen que la relevancia que se le otorga a los liderazgos políticos como agentes políticos termina legitimando a las elites en el poder, esto promueve la hegemonía de los líderes a través de organizaciones partidarias sobre "los gobernados". Estas organizaciones a través de la forma que va adquiriendo su estructura y las bases sociales que empiezan a perder, tienden a producir políticas públicas para mantenerse en el poder sin incentivar la participación política de la ciudadanía; es decir, el sistema político partidario desde una lógica realista-liberal tendería a monopolizar el poder sin contar con mecanismos de control ciudadano necesarios para contrarrestarlo ${ }^{61}$. Estos críticos entienden que ciertas versiones de la democracia realista ignoran los distintos tipos de desigualdades y en lugar de velar por los distintos derechos - en nombre de cuya protección se fundó- estaría reproduciendo las desigualdades económicas, sociales, culturales, etc., bajo un manto de legitimación institucional que obstaculiza la posibilidad de reacción frente a los problemas sociales. En esta línea, Young plantea que el modelo hegemónico de la democracia agregativa — en el que los distintos partidos ofrecen una plataforma de propuestas y se esfuerzan en la competencia por obtener preferencias ciudadanas - toma las preferencias como una "realidad dada" sin establecer criterios de evaluación sobre su calidad, no da lugar a la interacción democrática con otros, fundada en una racionalidad individual e instrumental y refuerza los mecanismos de exclusión democrática ${ }^{62}$. La escisión radical entre quienes deciden y aquellos sobre los que recaen las decisiones en este modelo agregativo-competitivo pone en riesgo la traducción de los intereses ciudadanos en políticas públicas equitativas, pasando por alto el compromiso intrínseco de la democracia con la justicia ${ }^{63}$.

Por su parte en Facticidad y validez Habermas analiza la "democracia empirista" a partir de la obra La Libertad que queremos: La decisión para la democracia liberal de Werner Becker (1937-2009). Sostiene que la concepción empirista de la democracia se basa en la preservación de dominio estatal que busca sostener y en el reconocimiento fáctico con que cuenta por parte de quienes se someten a él mediante un "libre

61 Downs, An Economic Theory of Democracy, p. 96.

62 Iris Marion Young, Inclusion and Democracy, Oxford University press, New York, 2000, pp. 19-20.

63 Iris Marion Young, "Communication and the other: beyond deliberative democracy", en Benhabib Seyla (ed.), Democracy and Difference: Contesting the Bounderies of the Political, Princeton University Press, Princeton, New Jersey, 1996, pp. 120 -121. 
asentimiento"64. Según esta concepción empirista sostenida por Becker, la democracia se basa en la competencia entre los partidos y en la votación ciudadana que empodera a los representantes de la ciudadanía en el gobierno, la voz última de la legitimidad está dada por el pronunciamiento de la mayoría ciudadana. Habermas objeta a la visión empirista que funda la validez de las normas democráticas en la voluntad misma de los individuos y arriba a un concepto "voluntarista de la validez"65. de este modo reduce la democracia a la fuerza de la mayoría. Si la fuente del poder democrático se redujera a la fuerza mayoritaria, sostiene Habermas, existiría una amenaza permanente del "partido numéricamente más fuerte o, por lo menos, simbólicamente más fuerte" sobre el resto de la población, y el poder democrático quedaría reducido a una cuestión de lucha de fuerzas fuera de cualquier marco institucional, lo cual produce la amenaza latente de $\operatorname{conflictos}^{66}$. Pero la amenaza latente de un conflicto civil, o incluso de una guerra frente a un posible desacuerdo generalizado, no garantiza a las minorías una protección sólida frente el poder de la mayoría, por más benevolente que esta sea. Si bien Becker recurre a las libertades fundamentales y al principio de la "rotación en el poder" para justificar la protección a las minorías, a partir de la concepción empirista sólo podemos inferir, sostiene Habermas, que las mayorías respetan esas libertades por el miedo potencial a formar parte en el futuro de las minorías. Esta comprensión "voluntarista de la validez normativa" pretende justificar el ejercicio del poder en la fuerza de la mayoría. Habermas le objeta que, desde esta perspectiva, el objetivo la lucha de los partidos políticos en el poder carece de toda dimensión de validez práctica ${ }^{67}$.

Por otra parte, Habermas entiende que el modelo de democracia empirista basado en la competencia proyecta el modelo del mercado hacia la sociedad civil, por tanto, traslada la lógica del subsistema económico al ámbito político ${ }^{68}$. Así busca satisfacer las demandas o intereses de ciertos grupos. Esta concepción concibe la política como técnica al servicio de la reproducción de la racionalidad instrumenta ${ }^{69}$ en tanto se propone ciertos medios para lograr ciertos fines a corto plazo, al mismo tiempo que desgastan los lazos sociales presentes en la sociedad civil, su capacidad de "integración social” es absorbida por la lógica de la "integración sistémica" del subsistema económico.

La sumisión de la política a la racionalidad instrumental produce distorsiones en el área comunicativa de las relaciones sociales y, por ello, podrían conducir a efectos democráticamente no deseados en la sociedad, por ejemplo, el desgaste de la legitimidad democrática, el triunfo de tradiciones locales no revisadas o el dominio de ciertos grupos de interés en la esfera pública ${ }^{70}$. Pero frente a cualquiera de estos escenarios se producen déficits democráticos o problemas sociales; por ejemplo, la pérdida de solidaridad intersubjetiva conduce a distintos problemas sociales. En esta línea, sostiene Javier Peña que a largo plazo esta ausencia implica gastos económicos de alto costo para la sociedad porque los procesos que se resuelven orgánicamente tendrán que ser costeados por el Estado ${ }^{71}$.

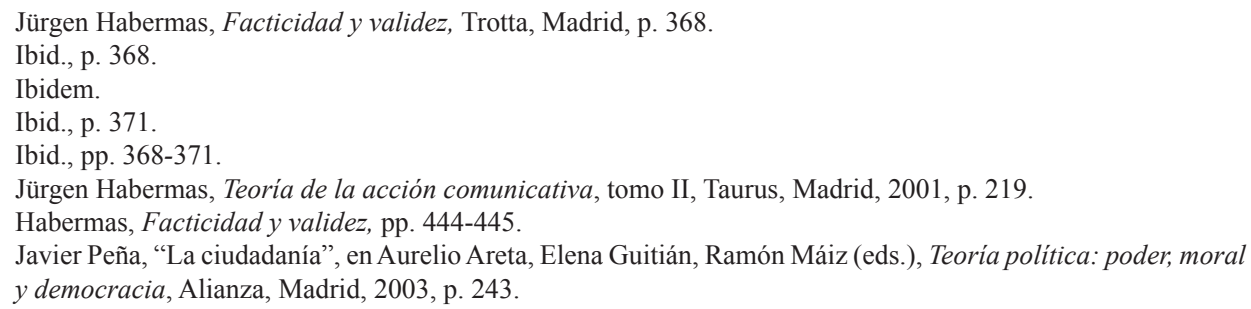


Estas críticas entienden que, las concepciones realista-liberales ponen en riesgo la subordinación de la democracia a otros subsistemas, tales como el mercado, la burocracia o la tradición local — como se afirmaba previamente-, los que disfrazados de legalidad podrían coronar las asimetrías sociales, de este modo, se pone la democracia al servicio de causas no - democráticas. La posibilidad de que los intereses privados se filtren en la esfera pública se torna amenazante en este contexto, debido a que el proceso de discusión que se restringe a la mera competencia electoral promueve una rivalidad que fundamentalmente agrega acríticamente preferencias, no promoviendo su discusión, análisis y crítica; así como tampoco un uso transparente y público de la información. Este reduccionismo atenta contra un balance informado y argumentado de las razones en favor y en contra de por qué implementar ciertas políticas públicas y no otras.

Desde distintas filas filosóficas no solamente se rechazan algunas máximas de este modelo democrático, sino que también se presentará otro como alternativa. Aquí aparece la democracia deliberativa como un modelo con potencial normativo para subvertir las presiones del mercado ${ }^{72}$ y de otros poderes hegemónicos que se filtran e imponen en la escena política. En la medida en que entiende que los procedimientos de diálogo y discusión intersubjetivos promueven la información y participación de los participantes en la deliberación, el procedimiento deliberativo generaría ciudadanías informadas en lo que refiere a los asuntos públicos, lo que resulta provechoso en la producción de políticas públicas equitativas, no solamente porque pueden originarse propuestas desde la ciudadanía, sino porque esta funciona como un sistema de control a las propuestas parlamentarias para evitar la reproducción de los poderes exógenos de carácter excluyente u opresivo de grupos minoritarios en la esfera pública.

En este sentido, la siguiente sección tiene por objetivo exponer las premisas centrales del modelo deliberativo para superar las debilidades del realismo-liberal. Con esta finalidad se pasará revista a algunas propuestas deliberativas.

\section{Democracia deliberativa: presentación del modelo}

El modelo de la democracia deliberativa surge como una alternativa crítica a las vertientes realistas-liberales de la primera ola, en este sentido si bien se presenta como un procedimiento formal en la toma de decisiones en el contexto de sociedades pluralistas donde conviven diversas concepciones comprensivas del bien, tiene como finalidad sustancial una cierta idea de equidad o ecuanimidad en los resultados que debe arrojar el proceso de decisión colectiva. La deliberación democrática enfatiza los aspectos procedimentales de la discusión, fundamentalmente, la justificación argumentativa de los agentes que participan en ella. Por ello pone a los sujetos en condiciones simétricas de discusión para incidir en el resultado final del proceso cuyos resultados han de recaer sobre sus propias vidas. Las condiciones simétricas en la comunicación garantizan la ecuanimidad del resultado. En esta línea postula que los sujetos que deliberan cuentan con igual capacidad para argumentar, posicionarse y finalmente arribar a su propio juicio acerca del tópico en cuestión. Gerald

72 Jon Elster, "The Market and the Forum: Three Varities of Political Theory", en James Boham y William Rehg (eds), Deliberative Democracy: Esssays on Reasons and Politics, The Massachusetts Institute of Technology Press, Cambridge, 1997. 
Cohen plantea la idealización del modelo deliberativo; esto supone ciertos principios tales como publicidad de la información, el intercambio argumentado de ideas y la apertura hacia el otro ${ }^{73}$. De este modo, la deliberación idealizada representa una forma particular de comunicación que rechaza otras formas de expresión que ponen en riesgo la transparencia de la información, formación de las preferencias, la equidad de la comunicación y formas distorsionadas de la comunicación tales como las amenazas, la manipulación o los sobornos ${ }^{74}$. Los defensores de la deliberación encuentran en la argumentación y el diálogo público en torno al bien común un ideal que vincula la consideración igualitaria de los intereses con los ideales del razonamiento público y la autonomía política ${ }^{75}$. Esta concepción considera relevante que el diálogo democrático sea siempre revisado e informado por el razonamiento público. Por ello considera que los intereses que pretendan imponerse en la esfera pública no pueden ser considerados como prepolíticos —a diferencia del modelo liberal-; se considera que estos intereses se forman en la propia dinámica política, es decir, que en el ejercicio del razonamiento público los mismos son transformados o revisados, reflexionados y eventualmente depurados. Este modelo afirma que aquellos intereses que no resisten el "test de la deliberación" no pueden ser universalizados para el colectivo y, por ende, carecen de fuerza normativa para regir sobre la comunidad política. Aunque los resultados de la deliberación siempre son indeterminados, es decir, no podemos preverlos de antemano, la defensa de un interés meramente personal o sectorial no sería defendible en la palestra pública y, por tanto, no podría prosperar.

Si bien podemos afirmar que los partidarios de la democracia deliberativa comparten ciertas premisas básicas sobre este modelo, no todos provienen de las mismas familias teóricas, por ello a continuación planteo un mapa general de distintos enfoques deliberativos que se diferencian por el énfasis en algunos aspectos sobre otros.

Desde la tradición del marxismo analítico, Jon Elster y Joshua Cohen postulan la deliberación como modelo de democracia. En esta línea sostienen que el razonamiento público funciona como mecanismo de justificación de decisiones legítimas. La idea de una justificación mediante el razonamiento público se representa en un procedimiento idealizado de deliberación política, la que pueda capturar las nociones de "libre, igual y razón que figuran el ideal deliberativo"76. El procedimiento deliberativo idealizado permite una caracterización paradigmática del razonamiento, el que puede servir de modelo para la toma de decisiones colectivas, vinculando el ejercicio del poder con la capacidad de razonamiento libre entre iguales ${ }^{77}$. La igualdad y libertad formal y sustantiva de los participantes forma parte de las condiciones ideales de la deliberación, los participantes "son y se ven recíprocamente como libres" del mismo modo que "se ven entre sí como formal y esencialmente iguales" . La libertad e igualdad de los individuos es inmune a los poderes extrapolíticos puesto que las normas que regulan el proceso deliberativo son ecuánimes, en el proceso deliberativo lo que pesan son las buenas razones que los individuos puedan aportar

\footnotetext{
73 Joshua Cohen, "Democratic Equality": Ethics, vol. 99, n. ${ }^{\circ} 4$ (1989), p. 128.

74 Mark Warren, Deliberative Democracy, Documentos de Trabajo de Doctorado de Ciencia Política, FLACSO, México, D.F., 1999, pp. 13-15.

75 Sheyla Benhabib, "Toward a deliberative model of democratic legitimacy", en Sheyla Benhabib, Democracy and Difference: Contesting the Boundaries of the Political, Princeton University Press, Princeton, 1996, p. 69.

76 Joshua Cohen, "Democracia y libertad" en La democracia deliberativa, Gedisa, Barcelona, 1998, p. 244.

77 Ibid., pp. 244-245.

78 Ibidem.
} 
y no los poderes o ventajas particulares con los que cada uno de ellos cuenten más allá del proceso deliberativo. En esta línea, Cohen sostiene que: "Los participantes son esencialmente iguales, pues la distribución existente del poder y los recursos no inciden en sus posibilidades de contribuir a la deliberación, y esta distribución no le otorga facultades decisivas en la deliberación"79. Cohen pretende fundamentar la separación entre el procedimiento deliberativo de las creencias sustantivas de la moral, en su visión idealizada. Concibe la deliberación a través del razonamiento público, de modo que excluye las presiones ajenas a la propia dinámica de la argumentación.

Si bien los trabajos de Elster y Cohen previamente citados son referencias constantes, la descripción de Jürgen Habermas de la democracia deliberativa es considerada modélica. Este modelo se inscribe en el marco de la teoría crítica del cuál el autor es un representante destacado. Por ello, parte del diagnóstico marxiano de la sociedad en un estado de dominación y opresión que produce distintas patologías en el mundo de la vida ${ }^{80}$, para la cual tanto científicos como filósofos tienen la tarea de producir un saber emancipatorio ${ }^{81}$.

La infraestructura normativa del modelo habermasiano se encuentra en los principios de la ética del discurso, donde el autor fundamenta su modelo político en los principios éticos trazados en Conciencia moral y acción comunicativa. En esta obra, Habermas plantea que, los principios éticos de la práctica discursiva están implícitos en la estructura de cualquier diálogo, incluso de aquel que quiera ocultar la verdad porque incluso la intención de engaño está orientada en la búsqueda de esta ${ }^{82}$. Las condiciones ideales de discurso suponen que nadie que cuente con la facultad de pronunciarse puede quedar excluido de la comunicación. Los individuos deben reconocerse recíprocamente como interlocutores iguales y cada uno debe tener derecho a exponer sus propios argumentos, la obligación de escuchar a los ajenos así como respetar la lógica de la mejor argumentación. Así mismo, sólo serán admitidos en el discurso aquellos hablantes que tengan las mismas posibilidades de acción comunicativa, por tanto, no debe haber fuentes de coacción dentro del procedimiento del discurso ${ }^{83}$. Los principios de la ética del discurso develan las estructuras de una situación ideal de habla que se mantiene inmune contra la desigualdad y por ello conduce a los hablantes a un equilibrio entre sus intereses particulares y antagónicos ${ }^{84}$. Cuando las condiciones ideales del habla guían el discurso se filtran los intereses parciales, y pesar de que en algunos contextos se produce algún tipo de coacción o manipulación que podrían violentar estas condiciones ideales, Habermas considera que ello no vulnera su validez porque “...cualquiera que esté en una relación comunicativa de algún tipo ya presupone la situación ideal de diálogo, aunque se desvíe tácticamente lo que quiera de sus postulados" ${ }^{\prime 5}$. La irrupción de disputas y rupturas

\footnotetext{
79 Ibidem.

80 Estas tesis forman parte del sistema trazado por Habermas en distintas obras, de las que se destaca Teoría de la acción comunicativa.

No me resulta posible poner en discusión las tesis primarias de la filosofía del autor porque debería extenderme más allá de los límites permitidos, pero respondiendo a los comentarios de uno de los árbitros: la concepción antropológica que asume Habermas es de origen hegeliano: el reconocimiento intersubjetivo.

81 Jürgen Habermas, Conocimiento e interés, Taurus, Buenos Aires, 1989, p. 308.

82 Jürgen Habermas, Aclaraciones a la ética del discurso, Trotta, Madrid, 2000, p. 18.

83 Jürgen Habermas, Conciencia moral y acción comunicativa, Editorial Trotta, Madrid, 1994, pp. 112-113.

84 Ibid., p. 93.

85 Robert Alexy, Teoría de la argumentación jurídica, Centro de Estudios Constitucionales, Madrid, 1989, pp. 129-130.
} 
en la comunicación no quiebra la validez de las condiciones ideales del habla; estas están presentes en el discurso como estructuras lingüísticas intersubjetivas. Para apartarse de las mismas el individuo debería excluirse de cualquier tipo de acción comunicativa y por eso debería dejar de lado su humanidad.

Una vez planteadas las premisas generales de la teoría de la deliberación habermasiana cabe preguntarnos si el autor visualizó algún mecanismo de instrumentalización, algunos de sus supuestos teóricos contradicen las investigaciones empíricas de la sociología que definen a la política como una competencia entre agentes interesados. En su célebre obra Facticidad y validez Habermas identifica una tensión externa entre la autocomprensión normativa de la democracia y los procesos políticos reales de los que dan cuenta las ciencias sociales, las que entienden la política esencialmente como una lucha estratégica por posiciones de poder ${ }^{86}$, sustentando la concepción empirista previamente expuesta. Para superar esta tensión, Habermas deberá realizar una traducción sociológica de la política deliberativa que consiste en pasar de una dimensión normativa, en la cual dé cuenta de cómo se institucionalizan los procesos de comunicación a la sociología de la democracia, la que define cómo ha de responder la teoría discursiva a la facticidad social. En esta línea realiza la traducción sociológica de la teoría deliberativa, donde la opinión pública ocupa un lugar central encarnando el poder comunicativo. En la opinión pública están las bases del poder comunicativo porque funciona como un sistema fluido de comunicaciones integrado en el mundo de la vida donde los individuos tienen su sociabilidad básica a través de la familia o los amigos. En el contexto de la democracia deliberativa las estructuras comunicacionales de la opinión pública funcionan como "una vasta red de sensores que reaccionan a la presión de problemas o situaciones problemáticas que afectan a la sociedad global, y estimulan opiniones diferentes"87. En la esfera de la vida privada de las personas está presente el público portador de la opinión pública, por ello las redes de comunicación del espacio público — tales como la familia, amigos, compañeros de trabajo o vecinos, etc. - están estrechamente conectadas con ámbitos de la vida privada. La opinión pública se origina en el ámbito más próximo al sujeto y se va expandiendo hacia vínculos más impersonales hasta generar una opinión con capacidad de reacción frente a discusiones sociales. Siguiendo el modelo de Bernhard Peters (1949-2005), Habermas presenta un modelo democrático de doble vía donde hay un centro y una periferia del sistema político: una opinión pública que emerge desde las periferias y una política institucionalizada que gobierna el centro del espacio público encarnada en el ámbito parlamentario ${ }^{88}$.

Por otra parte, Carlos Santiago Nino (1943-1993) influenciado por el liberalismo rawlsiano y por la teoría comunicativa habermasiana postula un modelo deliberativo que sintetiza aspectos relevantes de ambas vertientes teóricas y supera las aparentes debilidades de ambos modelos. Nino entiende que, el individualismo metodológico de Rawls es deficiente como recurso epistémico para acceder a verdades morales porque la reflexión monológica definida a partir de la satisfacción de ciertas exigencias como las de imparcialidad o universalidad presentan ciertas dificultades tales como: mantenerse fiel e imparcial frente a los intereses de los otros, la posibilidad de estar equivocados y que las conclusiones podrían carecen de prescripción para el

\footnotetext{
86 Habermas, Facticidad y validez, p. 302.

87 Ibid., p. 378.

88 Ibid., pp. 435-436.
} 
sujeto individual ${ }^{89}$. Dado que el proceso colectivo de reflexión es más confiable que la reflexión individual y que el primero no sería operativo si siempre decidiéramos estar obligados a seguir los resultados de nuestra reflexión individual, la obligación de observar aquello que ha sido decidido colectivamente se encuentra simplemente justificada ${ }^{90}$.

Por otra parte, Habermas sostiene un "constructivismo epistemológico" en el que se postula el acceso a la verdad moral mediante la decisión y discusión colectiva en el que se cumple con las condiciones del discurso y en el que participan todos los involucrados ${ }^{91}$. Según esta postura no hay principios morales válidos a priori sino como resultado de una discusión moral real, por ello la validez de los juicios morales no descansa en el resultado del discurso real sino en sus presupuestos: "ese resultado es una forma confiable de conocer los principios válidos". Esto parecería estar confirmado — afirma Nino — cuando Habermas sostiene que: "[El discurso práctico] es en realidad un procedimiento no para la producción de normas justificadas, sino para la comprobación de la validez de normas propuestas y establecidas con carácter hipotético"92. Nino repara en que Habermas realiza también otras afirmaciones que parecen colocarlo en una posición más radical que podría denominarse "constructivismo ontológico" y a partir de ella sostiene que la validez de los principios morales y no el mero conocimiento de esa validez se construye con el resultado de la discusión real cuando ella satisface ciertas condiciones. Así Habermas afirma que: “... los contenidos se elaboran de tal manera en el discurso que, al final, desaparecen los puntos de vista valorativos que no son susceptibles de acuerdo por consenso"93. A partir de lo anterior, Nino entiende que la concepción habermasiana acerca de la constitución de la verdad no refleja "la fenomenología de la discusión moral" porque esta no radica en la expresión de intereses personales - tal como Rawls y Habermas enfatizan - sino en postular criterios de validez o principios" ${ }^{94}$. En esta línea entiende que el "constructivismo epistemológico" carga con cierto "convencionalismo conservador" porque quienes participan de una discusión no pueden defender la validez de su propuesta dependiendo del resultado de la discusión; tampoco podrían defender un principio para la discusión sino hubiera razones fundadas para apoyarlos.

El "constructivismo epistemológico" que Nino postula, afirma que el conocimiento moral se produce a través de una práctica social ${ }^{95}$ y con esto pretende alejarse tanto de una concepción estática de las normas y valores morales (conservadurismo), como de un ideal de excelencia, independiente de los deseos o formas de vida de los individuos a los que el Estado le da preferencia imponiéndolas sobre las creencias particulares (perfeccionismo moral) ${ }^{96}$. La búsqueda de los principios morales se ubica en las antípodas de aquella posición que sostiene que lo "bueno para el individuo o lo que satisface sus intereses es independiente de sus propios deseos o elecciones de vida y que el Estado puede a través de distintos medios dar preferencia a aquellos

\footnotetext{
89 Carlos Santiago Nino, La Constitución de la democracia deliberativa, Gedisa, Barcelona, 1997, pp. 160-161.

90 Ibid., p. 165.

91 Carlos Santiago Nino, "Constructivismo epistemológico: entre Rawls y Habermas": Doxa Cuadernos de Filosofía del Derecho, n. ${ }^{\circ} 5$ (1988), p. 97.

92 Ibid., p. 94.

93 Ibidem.

94 Nino, La Constitución de la democracia deliberativa, p. 163.

95 Nino, "Constructivismo epistemológico: entre Rawls y Habermas", p. 87.

96 Carlos Santiago Nino, Ética y derechos humanos, Paidós, Buenos Aires, 1984, p. 136; pp. 258-259.
} 
intereses y planes de vida que son objetivamente mejores"97. El objeto de la deliberación no radica en el descubrimiento de la excelencia humana sino en la fundamentación de los valores morales que circulan en la convivencia humana de cierto momento histórico, en esta concepción se pone en juego el diálogo intersubjetivo que fundamenta los principios morales ${ }^{98}$.

El modelo deliberativo propuesto combina la tesis ontológica de que la verdad moral se define en tanto satisface los presupuestos formales de una práctica discursiva dirigida a la cooperación de las partes y la minimización de los conflictos, con la tesis epistémica que afirma que las verdades morales se alcanzan a través "la discusión y decisión intersubjetivas" 99 . Nino se separa de aquellas concepciones democráticas que pretenden deslindarse de la moral. Por lo contrario, entiende que la democracia supone la moralización de las preferencias de los individuos. En consonancia con esto, el autor resalta el valor epistémico de la democracia deliberativa, porque considera que la misma es una herramienta para develar la moralidad social, esto es acceder a los principios morales presentes en cierta comunidad social ${ }^{100}$. Por ello la deliberación tiene un valor adicional en el aporte que realiza al conocimiento de los sujetos, contribuye a la identificación de errores o debilidades del razonamiento, así como a identificar cuando una propuesta es injusta porque se funda en motivos egoístas o porque no se consideran los intereses de los demás y, finalmente, aporta en la evaluación personal de los intereses de todos los afectados ${ }^{101}$. La deliberación favorece el descubrimiento de estos contenidos, su problematización a través de la discusión pública para su posible legitimación y, finalmente, el logro de su aplicación. En esta línea comulga con los fundamentos de David Estlund para quién la legitimidad democrática tiene validez epistémica en tanto descansa en un procedimiento procesalmente justo y se celebra en base a razones que son potencialmente objetables para cualquier ciudadano razonable. Esta idea de legitimidad tiene un fuerte componente liberal por su respeto a la posibilidad de un "desacuerdo consciente" entre las partes; estás están sometidas a la posibilidad de examinar de modo constante sus creencias y argumentos ${ }^{102}$.

En síntesis, la concepción deliberativa de Nino aporta insumos teóricos a la "moralización de las preferencias" asumiendo un fundamento epistémico para las creencias, en la medida en que el proceso de discusión permite el hallazgo y la revisión colectiva bajo una prueba racional de la moralidad compartida por una comunidad determinada.

\section{Mecanismos de la democracia deliberativa para contrarrestar poderes exógenos}

En la sección anterior se pasó revista a las distintas tradiciones teóricas que consideran la democracia deliberativa como un procedimiento para arribar a decisiones

\footnotetext{
$97 \quad$ Ibid., p. 136.

98 Nino, La Constitución de la democracia deliberativa, p. 154.

99 Ibid., p. 161.

100 Ibid., p. 154.

101 Ibid., p. 161.

102 David Estlund, "Beyond Fairness and Deliberation: The Epistemic Dimension of Democratic Authority", en James Bohman y William Rehg (eds.), Deliberative Democracy: Essays on Reasons and Politics, Massachusetts Institute of Technology, Massachusetts, 1997, pp. 175-176.
} 
políticas expresadas en ciertas leyes jurídicas que velan por un bien colectivo racionalmente fundado, pero: ¿con qué recursos cuenta este modelo para frenar los poderes hegemónicos que se imponen en la escena política? ¿Presenta la democracia deliberativa la fortaleza teórica que entiende que le falta al modelo anterior? ¿Corre el riesgo de metabolizar presiones de grupos particulares disimuladas en un interés colectivo? A partir de las tradiciones teóricas que se distinguieron en el apartado anterior, a continuación, se señalan tres posibles recursos de la deliberación democrática para contrarrestar los poderes hegemónicos en el escenario político.

\subsection{La trasformación de las preferencias y la búsqueda de su autonomía: Cohen y Elster}

Desde la perspectiva de Cohen y Elster una de las fortalezas de la democracia deliberativa es el ideal de autonomía por el cual este modelo de democracia pretende salvaguardar la autodeterminación de los sujetos frente a fuentes exógenas de poder. Elster entiende que la autonomía es una noción compleja, pero que podría entenderse como la capacidad del sujeto para escoger, adquirir o modificar deliberadamente ciertos deseos; si bien implica a la racionalidad para revisar los contenidos desiderativos, no se identifica con la bondad ética ${ }^{103}$. Afirma que la autonomía es análoga al juicio, en tanto que tiene el mismo rol para los deseos que el juicio para las creencias. Esta concepción de la autonomía toma distancia de los deseos, pero no los abandona; es cercana a la filosofía estoica y spinoziana ${ }^{104}$ en tanto entiende la autonomía como capacidad de autodeterminación racional.

Siguiendo este modelo de autonomía, Elster y Cohen entienden que este tipo de democracia busca sortear la manipulación que distintos mecanismos de presión o fuerza opresiva se ejerza sobre los individuos. La democracia deliberativa refuerza la capacidad subjetiva promovida por una estructura institucional de transformar las preferencias de los individuos, de este modo se pretende contribuir a la autodeterminación de estos, con miras a la conformación de una voluntad no alienada. Ambos autores describen lo que entienden como amenazas centrales para la autonomía de los sujetos. La primera es definida por Elster como "preferencias adaptativas"; estas son preferencias que son transformadas por las circunstancias en las que el sujeto se halla inmerso, sin una contribución relevante de sí mismo en el cambio. En esta línea, Elster sostiene que los deseos o las preferencias no son autónomas cuando se adaptan a aquello que el sujeto ve como posible ${ }^{105}$. Para ilustrar esto recurre al mito del zorro y las uvas dónde ante la imposibilidad de alcanzar las uvas, el zorro termina por considerarlas no apetecibles por la amargura que supone presentes en ellas. En este ejemplo se visualiza cómo las preferencias adaptativas suponen el ajuste de la volición a las posibilidades reales que se le presentan al sujeto de manera no deliberada y no consciente por él mismo ${ }^{106}$. La segunda amenaza a la autonomía es la que el mismo Cohen denomina como "preferencias acomodaticias" que, si bien a diferencia de las anteriores se forman deliberadamente, "representan ajustes psicológicos a condiciones de subordinación en las que no se reconoce a los individuos la capacidad

103 Jon Elster, Uvas amargas: sobre la subversión de la racionalidad, Ediciones Península, Barcelona, 1998, pp. 36-37.

104 Ibidem.

105 Ibid., p. 42.

106 Ibid., pp. 160-161. 
de autogobierno"107. Para ilustrar el caso de las "preferencias acomodaticias", Cohen toma como ejemplo a los esclavos estoicos que ajustan su voluntad de ser esclavos al deseo que sus circunstancias les ofrecen y, a su vez, no se les presenta ninguna instancia deliberativa para revisarlas ${ }^{108}$.

Ambas amenazas a la autonomía son contempladas en los diseños institucionales deliberativos, en la medida en que se pone en práctica la igual capacidad de revisión y discusión pública, las relaciones de poder y de subordinación son susceptibles de neutralización poniendo en jaque tanto a las preferencias adaptativas (universalidad de la razonabilidad) como a las acomodaticias (universalidad de la capacidad de deliberar). En este sentido, afirma Cohen:

La formación de preferencias a través del procedimiento deliberativo resulta consistente con la autonomía, dado que las preferencias que se forman mediante la deliberación pública no están simplemente dadas por las circunstancias externas. Al contrario, son el resultado del poder de la razón ejercido a través de la discusión pública ${ }^{109}$.

La razonabilidad del procedimiento deliberativo obliga a la revisión constante de las preferencias cuyo origen primero es el mundo social, forjando la formación autónoma de las mismas. De este modo se pretende sortear la formación de preferencias no autónomas (ya sean adaptativas o acomodaticias) que subordinen al sujeto a algún tipo de autoridad o circunstancia aleatoria de las que no sea partícipe.

A pesar de este procedimiento de revisión constante de preferencias que por naturaleza son acríticas, el riesgo de que la deliberación enmascare intereses individuales o sectoriales en nombre del bienestar colectivo de los involucrados permanece latente. Sin embargo, nos pone en aviso sobre la necesidad de vigilancia constante sobre el proceso de discusión deliberativo.

\subsection{El ejercicio de la razón comunicativa: Habermas}

Desde la perspectiva de Habermas la democracia deliberativa es un modelo que pretende contrarrestar el avance de la racionalidad instrumental moderna cuyo avance ya había sido objetado por la primera generación de la escuela de Frankfurt. En el marco de la teoría crítica, el frankfurtiano afirma que la racionalidad instrumental no sólo ha producido la burocratización y la mercantilización de distintas esferas del mundo de la vida, sino también el socavamiento de la solidaridad intersubjetiva ${ }^{110}$. Insertada en la pragmática del lenguaje, la racionalidad comunicativa puede ejercer su función liberalizadora contribuyendo a la comunicación y al entendimiento de los individuos en sus relaciones diarias en el mundo de la vida ${ }^{111}$. En la medida en que el poder comunicativo puede contrarrestar los poderes patológicos del mercado ${ }^{112}$, los discursos prácticos de los ciudadanos pueden reorientar la toma de decisiones en los estados modernos; a partir del procedimiento deliberativo este poder puede ins-

\footnotetext{
107 Cohen, "Democracia y libertad", p. 136.

108 Ibidem.

109 Ibidem.

110 Habermas, Teoría de la acción comunicativa, pp. 219-220.

111 Ibid., pp. 258-261.

112 Habermas, Facticidad y validez, p. 363-393.
} 
titucionalizarse. En la opinión pública están las bases del poder comunicativo. Esta funciona como un sistema fluido de comunicaciones integrada al mundo de la vida donde los individuos tienen su sociabilidad básica a través de la familia o los amigos $^{113}$. En el contexto de la democracia deliberativa las estructuras comunicacionales de la opinión pública tienen la facultad de reaccionar o presionar ante problemas o situaciones que afectan a una comunidad determinada o a la sociedad global. ¿Cómo se produce el contrapoder desde la perspectiva habermasiana? Se considera que la deliberación es un procedimiento que institucionaliza el razonamiento público y por ello formaliza condiciones ideales de decisión pública, esta línea Habermas considera que la articulación entre deliberación y democracia se produce bajo la forma ideal de los principios del discurso en la que todos los sujetos afectados participan equitativamente del mismo. A partir del ejercicio discursivo emerge un poder comunicativo potencialmente presente en la sociedad civil, cuando este ejercicio se pone en acción, es un recurso que oficia de contrapeso para una racionalidad instrumental que burocratiza o mercantiliza todos los órdenes de la vida social. Habermas le asigna a la sociedad civil un papel relevante en el proceso de la emancipación social, en la medida en el que en este cuerpo social está presente la posibilidad de liberarse de los poderes opresivos que en el avance de la racionalidad instrumental se pretenden imponer en la vida social ${ }^{114}$. El poder comunicativo tiene la capacidad de subvertir la racionalidad instrumental. Por ello es fuente de normatividad jurídica y de decisiones políticas equitativas con las partes involucradas.

\subsection{El fundamento epistémico para las propuestas democráticas: Nino}

En el caso del modelo planteado por Nino, el valor de la democracia radica en su cualidad epistémica, la que se asienta en la argumentación, las decisiones mayoritarias y la capacidad de negociación entre las partes ${ }^{115}$. Se entiende que un proceso informado, dialógico y participativo genera decisiones legítimas para los individuos, los que quedarían protegidos de ser objeto del interés arbitrario de algún sector en particular. Nino sostiene que: "cuando las condiciones para promover el valor epistémico de la democracia no son satisfechas, ésta no logra su valor"116 puesto que estas condiciones permiten evaluar las democracias reales sobre el ideal normativo. Por ello una multitud sujeta a "emociones extraordinarias" aclamando a un líder en un espacio público estaría lejos de capturar el valor epistémico, en el que más que en la participación espontánea y emotiva de los ciudadanos se funda en el respeto a un procedimiento de discusión y decisión mayoritaria y equitativa de los involucrados $^{117}$. La concepción de democracia deliberativa de Nino oficiaría de contrapoder, en la medida en que pretende combinar la inclusión de los involucrados con el fundamento moral de las creencias que se sostienen. Según este criterio, quedarían excluidas del ámbito democrático aquellas propuestas que pretendieran imponer un poder que no esté fundado exclusivamente en razones morales, dejando afuera diversas formas de exclusión de la discusión pública. En suma, la fortaleza epistémica del modelo es la columna vertebral para el rechazo de propuestas heterónomas que se

113 Ibid., pp. 440-441.

114 Ibid., pp. 439-441.

115 Nino, La Constitución de la democracia deliberativa, p. 176.

116 Ibid., p. 180.

117 Ibid., p. 181. 
presentan como sistema de creencias ideológico, tales como el rechazo a pretendidas argumentaciones basadas en creencias racistas, machistas u homofóbicas.

\section{Conclusión}

El presente trabajo expuso distintas versiones del núcleo normativo de la familia realista-liberal donde a grandes rasgos se expusieron sus concepciones de participación política, las que van desde la defensa del liderazgo político hasta las que se encarnan en la idea de poliarquía. Se explicitó que si bien este modelo parte de la descripción del funcionamiento democrático, no está exento de normatividad en tanto modeliza la democracia y, en sobre todo en su segunda formulación, la evalúa como eficiente cuando recoge e incluye preferencias ciudadanas. Posteriormente, se reconstruyeron algunas críticas que los teóricos deliberativos realizan al realismo-liberal sobre las dificultades de esta familia teórica para generar políticas públicas receptivas a las preferencias y demandas de los ciudadanos minoritarios y para sortear los poderes exógenos a la política que algún grupo de poder quisiera imponer sobre la misma. En esta línea, se presentaron tres mecanismos del modelo deliberativo para enfrentar estas debilidades: (1) el combate a las preferencias adaptativas o acomodaticias; (2) la instauración de un poder comunicativo; (3) las exigencias de una fundamentación epistémica.

El modelo deliberativo se presentaría entonces con mayor potencial para la inclusión de las preferencias ciudadanas respecto al modelo anterior, en la medida en que se funda en ciertos compromisos éticos y epistémicos para hacer frente a distintos riesgos democráticos como el dominio de grupos de poder en la esfera pública o de ciertas creencias discriminatorias carentes de fundamentos que se presentan en la vida social como naturales.

La presente conclusión no significa que la deliberación esté exenta de objeciones, diversos teóricos también señalan la problematicidad de sus supuestos - como una excesiva confianza en la razón práctica para dirimir conflictos y alcanzar consensos y una concepción antropológica idealizada de un sujeto que le cede el paso a la razón frente a sus pasiones - pero abordar esto trasciende los propósitos que aquí me propongo.

\section{Referencias bibliográficas}

Alexy, Robert, Teoría de la argumentación jurídica, Centro de Estudios Constitucionales, Madrid, 1989.

Benhabib, Sheyla, "Toward a Deliberative Model of Democratic Legitimacy", en Sheyla Benhabib, Democracy and Difference: Contesting the Boundaries of the Political, Princeton University Press, Princeton, 1996.

Bobbio, Norberto, El futuro de la democracia, Planeta Agostini, Barcelona, 1989.

Cohen, Joshua, "Democratic Equality": Ethics, vol. 99, n. ${ }^{\circ} 4$ (1989), pp. 727-751.

—, "Democracia y libertad", en La democracia deliberativa, Gedisa, Barcelona, 1998.

Dahl, Robert, "The Concept of Power": Behavorial Sciences, vol. 2, n. ${ }^{\circ} 3$ (1957), pp. 315 317.

_, Who Governs?, Yale University Press, Massachusetts, 1976. 
—, La poliarquía: participación y oposición, Madrid, Tecnos, 1989.

—, La democracia y sus críticos, Paidós, Buenos Aires, 1991.

Downs, Anthony, An Economic Theory of Democracy, Harper Collins Publishers, New York, 1957.

Elster, Jon, "The Market and the Forum: Three Varities of Political Theory”, en James Boham y William Rehg (eds), Deliberative Democracy: Esssays on Reasons and Politics, The Masachussets Institute of Technology Press, Cambridge, 1997.

—, Uvas amargas: sobre la subversión de la racionalidad, Ediciones Península, Barcelona, 1998.

Estlund, David, "Beyond Fairness and Deliberation: The Epistemic Dimension of Democratic Authority", en James Bohman y William Rehg (eds.), Deliberative Democracy: Essays on Reasons and Politics, Massachusetts Institute of Technology, Massachusetts, 1997.

Habermas, Jurgen, Conocimiento e interés, Taurus, Buenos Aires, 1989.

-, Conciencia moral y acción comunicativa, Editorial Trotta, Madrid, 1994.

-, Aclaraciones a la ética del discurso, Editorial Trotta, Madrid, 2000.

—, Teoría de la acción comunicativa, tomo II, Taurus, Madrid, 2001.

-, Facticidad y validez, Trotta, Madrid, 2010.

Held, David, Modelos de democracia, Alianza, Madrid, 1992.

Macpherson, Crawford Brough, La democracia liberal y su época, Alianza, Madrid, 1997.

Nino, Carlos Santiago, Ética y derechos humanos, Paidós, Buenos Aires, 1984.

-, "Constructivismo epistemológico: entre Rawls y Habermas": Doxa. Cuadernos de Filosofía del Derecho, n. ${ }^{\circ} 5$ (1988), pp. 87-105.

—, La Constitución de la democracia deliberativa, Gedisa, Barcelona, 1997.

Pateman, Carole, Participación y teoría democrática, Prometeo, Buenos Aires, 2015.

Peña, Javier, "La ciudadanía”, en Aurelio Areta, Elena Guitián, Ramón Máiz (eds.), Teoría política: poder, moral y democracia, Alianza, Madrid, 2003.

Przeworski, Adam, Qué esperar de la democracia: límites y posibilidades del autogobierno, Siglo Veintiuno, Buenos Aires, 2010.

Sartori, Giovanni Teoría de la democracia, Alianza, Madrid, 1987.

—, ¿Qué es la democracia?, Taurus, Madrid, 2003.

Schumpeter, Joseph, Capitalismo, socialismo y democracia, Folio, Barcelona, 1984.

Tivey, Leonard, "Robert Dahl and American Pluralism", en Leonard Tivey y Anthony Wright (eds.), Political Thought since 1945: political, science, ideology, Edward Elgar Publishing Limited, England, 1992.

Warren, Mark, Deliberative Democracy, Documentos de Trabajo de Doctorado de Ciencia Política, FLACSO, México D.F., 1999.

Weber, Max, El Político y el científico, Alianza, Madrid, 1998.

—, Economía y sociedad, Fondo de Cultura Económica, México, 1964.

Young, Iris Marion, "Communication and the Other: Beyond Deliberative Democracy", en Benhabib Seyla (ed.), Democracy and Difference: Contesting the Bounderies of the Political, Princeton University Press, Princeton, New Jersey, 1996.

_, Inclusion and Democracy, Oxford University press, New York, 2000. 